UDC 611.018.32:57.085.23:576.08

Rybachuk O. A. ${ }^{1,2,3}$, Kyryk V. M. ${ }^{3}$, Poberezhnyi P. A. ${ }^{3}$, Butenko G. M. ${ }^{3}$, Skibo G. G. ${ }^{1,2,3}$, Pivneva T. A. ${ }^{1,2,3}$

${ }^{1}$ Bogomolets Institute of Physiology NAS Ukraine, Kyiv, Ukraine

${ }^{2}$ State Key Laboratory of Molecular and Cell Biology, Kyiv, Ukraine

${ }^{3}$ State Institute of Genetic and Regenerative Medicine NAMS Ukraine, Kyiv, Ukraine

e-mail: oks-ribachuk@yandex.ru

\title{
EFFECTS OF BONE MARROW MULTIPOTENT MESENCHYMAL STROMAL CELLS ON THE NEURAL TISSUE AFTER ISCHEMIC INJURY IN VITRO
}

\section{ABSTRACT}

Stem cells application in neural system injuries is an actual and prospective scientific field of modern regenerative medicine. In recent years much attention has been paid for study of regenerative effects of multipotent mesenchymal stromal cells (MMSCS) from different sources on injured tissues.

The aim of our study was to determine the level of tissue damage in hippocampus after in vitro model of ischemia and to investigate the effect of bone marrow MMSCs in non-contact co-culture with ischemic neural tissue. The ischemic injury of neural tissue in vitro was modeling in organotypic hippocampal slice culture (OHCS) by oxygen-glucose deprivation (OGD). Immunohistochemical analysis after 24 hours of BMMMSCs co-cultivation with OHCs after ischemia showed a significant reduction of caspase-3-positive dead neural cells, as compared to those in ischemic damage without BM-MMSCs co-cultivation, and reducing of glial cells activation. After co-cultivation of OHCS after OGD with BMMMSCs there remained cytoarchitectonics of the neural tissue.

Analyzing of our data, the neuroprotective effects of BM-MMSCs in non-contact co-cultivation with ischemic hippocampal organotypic slice culture is shown.

KEYWORDS: multipotent mesenchymal stromal cells, hippocampal organotypic slice culture, oxygen-glucose deprivation, co-cultivation, immunohistochemical staining.

Ischemic brain lesions are the third most common cause of death in developed countries. It may be the result of both, focal circulatory disorders and transitory cerebral ischemia, caused by a temporary cardiac dysfunction. Ischemic brain injury - ischemic stroke or cerebral infarction - is the result of vessels occlusion with microthrombus after atherosclerotic plaques disruption. Ischemic damage of brain tissue is a result of a number of interrelated processes that develop across time and space [1]. Development of effective treatment methods of this pathology requires further study of molecular and cellular mechanisms of processes, resulting from cerebral blood flow disorders. In the early developmental stages they are largely associated with changes in the biophysical characteristics of the mechanisms that provide the integrative function of neurons: synaptic transmission and functioning of ion channels, including responsible for electrical excitability [1,2]. These mechanisms play an important role in both natural and artificial neuroprotective effects.
There are many treatments for a stroke, but they are not perfect. At present, much attention is paid to cell therapy. In particular, since the late $20^{\text {th }}$ century there is implemented an international program for the study of stem cells potential, including bone marrow origin. This may result in a significant progress in the treatment of neurodegenerative diseases [3-5].

Multipotent mesenchymal stromal cells (MMSCS) are a population of cells with high adhesive ability in vitro. They are characterized by a significant proliferative activity and maintenance their stemness. They also can differentiate in vitro into chondrocytes, osteocytes, adipocytes; and other types of cells in conditions for induction a specific differentiation way $[6,7,8]$.

The most common MMSCs sources are bone marrow, cord blood, adipose tissue, Wharton's jelly, placenta, umbilical vein, amniotic fluid, amniotic membrane, synovial fluid, skeletal muscles, liver and, even, cord 
or peripheral blood [9]. MMSCs subpopulations are usually heterogeneous by self-renewal capacity and potential to differentiation [8, 9].

Using flow cytometry with a large number of surface markers we demonstrated that cultured population of human bone marrow MMSCs is homogeneous for more than $98 \%$. Under certain conditions in vitro these cells are easily differentiated. MMSCs co-cultivation with hematopoietic stem cells (HSCS) showed that MMSCs can maintain viability or even division of HSCs, herewith MMSCs form functional stroma [10]. In the culture of stromal progenitor cells and HSCs, MMSCs serve as a feeder for the survival of all hematopoietic cell clones. In addition, MMSCs can synthesize cytokines to support vitality of hematopoietic cells.

Around the world much attention is paid to study of MMSCs properties, carrying out fundamental and clinical researches. This interest is due to many factors, including relative ease of cultivation, existence or possibility of finding specific markers, immune suppression at the use of allogeneic material and so on. Unique potential of MMSCs has already been used to restore the functioning of damaged organs [11].

In terms of tissue niches formation an interesting fact is an interaction of stem cells of various origins among themselves and with differentiated cells of a microenvironment. Such interaction determines self-support of progenitor cells and/or direction of their further differentiation. However, the mechanisms and peculiarities of this intercellular interaction in the modified oxygen content are not completely understood. In the model of co-cultivation of hematopoietic and stromal progenitor cells there has been shown that, under conditions of low oxygen content in vitro, MMSCs actively support hematopoiesis and enhance the formation of hematopoiesis site with subsequent differentiation of hematopoietic precursors. There increases a part of stromal cells, in which an adhesion molecule VCAM-1 is expressed and the synthesis of interleukins (IL-6, IL-8) activates.

In studies in vitro, it was found that MMSCs have unique immunomodulatory properties, due to absence of their immunogenicity, and capacity to inhibition of proliferation and activation of lymphocytes. At co-cultivation of lymphocytes with MMSCs there was a change of population composition of immunocompetent cells by reducing the proportion of embryonic cells, increasing the proportion of CD34+-cells and suppression of $T$-cells activation. Reducing the oxygen content additionally inhibits the ability of $T$-cells to $H L A-D R$ antigen presentation [12]. MMSCs have immunosuppressive effect and therefore may provide tolerogenic effect in allogeneic transplantation. In vitro system MMSCS prevent maturation of dendritic cells, block proliferation of T-lymphocytes, inhibit chemotaxis and differentiation of $B$-lymphocytes, and induce the reproduction of regulatory $T$-cells [13]. Proceeding from this, mechanisms of contact and indirect interference are involved in interaction of MMSCs and immunocompetent cells from different subpopulations. Dynamic changes in levels of cytokines, growth factors and oxygen create unique niche in terms of such interaction [12].

During co-cultivation of murine MMSCS with cells from the fetal murine midbrain, a greater number of MMSCs with markers of neurons $($ NeuN $)$ and astroglia (GFAP) was shown. The results of these experiments confirmed the hypothesis that direct contact between cells (in addition to transmitting signals by trophic factors and cytokines) is important for differentiation of MMSCs. Apart from retinoic acid as a factor of MMSCs differentiation into neuron-like cells, there is used dimethyl sulfoxide, butylated hydroxyanisole, butylated hydroxytoluene and $\beta$-mercaptoethanol in a serum-free medium. Other ways of inducing neural differentiation in vitro are also applied. For example, the use of 5-azacytidine - demethylating substance that can modify gene expression in a medium that contains a mixture of nerve growth factor (NGF), brain-derived neurotrophic factor (BDNF) and neurotrophic factor (NTF). Also there was investigated an effect of neural inducer noggin, an agent capable to diffusion, which mediates neural induction at early stages of embryogenesis and neurogenesis in adults. These data indicate that neurons formed processes; there were found specific markers and «neural» genes in them; cells began to respond to the action of depolarizing stimuli as functionally mature neurons [14].
Therefore, regenerative properties of MMSCs in ischemic brain damage can be considered as one of the most effective recovery methods of damaged tissue morphological and functional state.

Thus, the aim of this study was to determine the level of damage to the hippocampal tissue cells in a model of ischemia in vitro and to investigate the effect of BM-MMSCs at their co-cultivation with ischemic tissue.

\section{MATERIALS AND METHODS}

All operations with experimental animals were conducted in accordance with the Law of Ukraine "On protection of animals from cruelty,» «European Convention for the protection of vertebrate animals used for experimental and other scientific purposes", as well as the principles of bioethics and biosafety regulations. [15]

Isolation of hippocampal organotypic slice culture (OHCs).

Hippocampal slices were prepared from 8-9-day-old FVB wild-type mice. The animals were decapitated, and the brain was isolated from the brainpan. Isolation and cultivation of hippocampal slices were performed by L. Stoppini: hippocampi were isolated from the brain in the cooled medium (50\% MEM, $5 \mathrm{mM}$ Tris, $12,5 \mathrm{mM}$ Hepes, $25 \%$ of $10 x$ salt solution HBSS, $p H=7,3$ ) [16]. Slices were cut by an automatic chopper (Mclllwain, UK), perpendicular to the longitudinal axis of the hippocampus, 350-375 $\mu \mathrm{m}$ thick. Then they were cultured for 5-7 days. Cultivation of organotypic slices was carried out on semipermeable membranes located on gas (a mixture of air with $5 \% \mathrm{CO}_{2}$ ) and liquid (50\% MEM, 25\% Hanks balanced salt solution, $15 \mathrm{mM}$ D-glucose, $25 \%$ inactivated horse serum, $\mathrm{pH}=7,2$ ) phase at 37 ${ }^{\circ} \mathrm{C}$. Culture medium was changed on the second day of incubation, and then two or three times a week. Within 5-7 days of culturing, hippocampal slices were completely cleaned from cells, damaged during allocation, and reached stable condition. During this time slices smoothed, their thickness decreased from 300-400 $\mu \mathrm{m}$ to $200-250 \mu \mathrm{m}$.

To detect damaged cells we used staining of cultured slices with propidium iodide $(P I)$, a stable fluorescent dye, which penetrates into cells with damaged membrane, binds to DNA molecule and acquires red

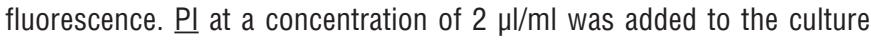
medium prior to the oxygen-glucose deprivation. Cultures were analyzed by fluorescent microscope XSP-139A-TP. For the experiment there were selected slices without any $P I$ staining detected.

\section{Modeling of ischemic hippocampal damage in vitro}

Oxygen-glucose deprivation (OGD) was created by keeping slices in a special chamber, in which oxygen in the air was replaced by nitrogen, and glucose in the culture medium was replaced with sucrose. OGD period lasted for 10 minutes. Further slices were returned to normal cultivation conditions for 2 hours - normoxic reoxygenation.

\section{Isolation and cultivation of BM-MIMSCs}

Bone marrow cells were obtained from $F V B$-mice ( 3 months old) by washing them from the femurs with medium RPMI-1640 (Sigma, USA) in sterile conditions. We plated $4 \cdot 10^{5}$ cells $/ \mathrm{cm} 2$ and cultured for 2 weeks, changing the culture medium every 2-3 days. Cultivation was carried out in $\mathrm{CO}_{2}$-incubator under conditions of humidified air with $5 \% \mathrm{CO}_{2}$ at +37 ${ }^{\circ} \mathrm{C}$ [17]. Nutrient medium RPMI-1640:DMEM (1:1) contained 15\% fetal bovine serum (Sigma, USA) and $2 \mathrm{mM}$ L-glutamine.

The first passage was performed at $80 \%$ confluence of monolayers removing cells with $0.05 \%$ trypsin solution. Then they were transplanted into a new bottle with a density $2 \cdot 10^{4} \mathrm{cells} / \mathrm{cm}^{2}$.

At second passage BM-MMSCs were plated in 6-well plates at $1.5 \cdot 10^{5}$ into each well and cultured for seven days.

Phenotyping of BM-IMMSC cell cultures

Phenotyping of cell cultures for markers CD34, CD44, CD45, CD73, CD90, CD117 was performed using fluorochrome-labeled monoclonal 
antibodies to mouse membrane antigens. We added monoclonal antibodies to $2 \cdot 10^{5}$ cells in $50 \mathrm{ml}$ of suspension at the rate of $0.5 \mu \mathrm{g} / 10^{6}$ cells and incubated them for 20 minutes at $4{ }^{\circ} \mathrm{C}$. After incubation, cells were washed twice in buffer CellWash (Becton Dickinson, USA). Then we carried out analysis with the cell sorter BD FACSAria (Becton Dickinson, USA) using the BD FACSDiva 6.1.2 software. To set up compensation of overlapping emission spectra of fluorochromes in multivariable analysis, there were used control samples of cells without antibodies (unstained control); samples with each of the antibodies separately (single stained control); and samples with a combination of several antibodies without one of them (fluorescence minus one control). The level of surface markers expression was measured in percentages and statistically calculated using Mann-Whitney U-test.

The percentage of dead and viable BM-MMSCs was determined with the BD FACSAria cell sorter by level of entry into cells with damaged membrane $7-A A D$. The percentage of viable cells in the culture was $93.6 \pm 0.5 \%$

The resulting cell cultures have satisfied the minimal criteria of MMSCs by phenotype and ability to directed multilinear differentiation $[18,19]$.

Co-cultivation of BM-MMSCs with ischemic neural tissue and its immunohistochemical evaluation

Cultured on semipermeable membranes hippocampal slices after short-term OGD were placed in 6-well plates, where BM-MMSCs were previously (7 days) cultivated. BM-MMSCs culture medium was replaced prior to co-cultivation. Within 24 hours after co-cultivation $\mathrm{OHCS}$ were fixed and immunohistochemical analysis was performed.

To identify neurons and glial cells there was used a double immunohistochemical staining with antibodies to astrocyte marker GFAP (chicken polyclonal, 1:1500, Dako, Denmark); neuronal marker NeuN (mouse monoclonal, 1:1000, Chemicon, UK); microglia cells marker Iba-1 (rabbit polyclonal, 1:750, Molecular Probes Inc., USA); a marker of apoptotic nuclei caspase-3 (rabbit polyclonal, 1:200, Molecular Probes Inc., USA).

Organotypic hippocampal cultures were fixed with $4 \%$ formaldehyde solution, washed with $0.1 \mathrm{M}$ phosphate buffered solution $(P B)$, treated with a solution of $0.3 \%$ Triton $X-100,0.5 \%$ bovine serum albumin
$(B S A)$ for better penetration of antibodies and prevention an excessive nonspecific combining. Within 24 hours hippocampal cultures were incubated in a mixture of primary antibodies. After washing in $0,1 \mathrm{M}$ $P B$, slices were treated for 1 hour with a compound of secondary antimouse Alexa Fluor-555-conjugated (1:1000, Invitrogen, USA), anti-rabbit Alexa Fluor-488-conjugated and anti-chicken Alexa Fluor-647-conjugated antibodies (1:1000, Invitrogen, USA)

After washing in $0.1 \mathrm{M} P B$ cultures were fixed with cover glass in a special medium for fluorescent preparations (Dako, Denmark). Hippocampal slices were studied using confocal microscopy FluoView TM FV1000 (Olympus Inc., USA) with a digital camera combined with a computer.

\section{RESULTS AND DISCUSSION}

One of the advanced research methods in cell and molecular biology is the cultivation of cells and tissues. Systems in vitro are a convenient experimental tool for precise control, subtle manipulations and long-term monitoring of normal and pathological processes in different tissues and, particularly, in the nervous tissue.

Therefore, an object of our research was organotypic hippocampal cultures. The hippocampus is a structure of the brain responsible for learning, memory and spatial orientation. Along with cerebral cortex and striatum, it is extremely sensitive to the damaging effects, in particular, the lack of oxygen and glucose [20-22]. The hippocampus is one of the most sensitive parts of the brain during ischemic injury with selective damage of pyramidal neurons in str. pyramidale CA1 area [23-24]. Glia actively participates in the control of neuronal activity and synaptic transmission in normal and different pathological conditions [25].

Microscopic analysis of hippocampal organotypic cultures in control samples without $O G D$ showed that hippocampal tissue retained the typical topography of cell layers and zones that are characteristic of the hippocampus in vivo, such as neurons in CA1 area located in the middle of slice (4-8 layers of pyramidal cells) and have a traditional pyramidal shape (Fig. 1). Glial cells evenly localized in all layers of the CA1 area of the hippocampus. A layer of glial cells adjoins to the surface of semipermeable membrane with thin spikes, providing fixation
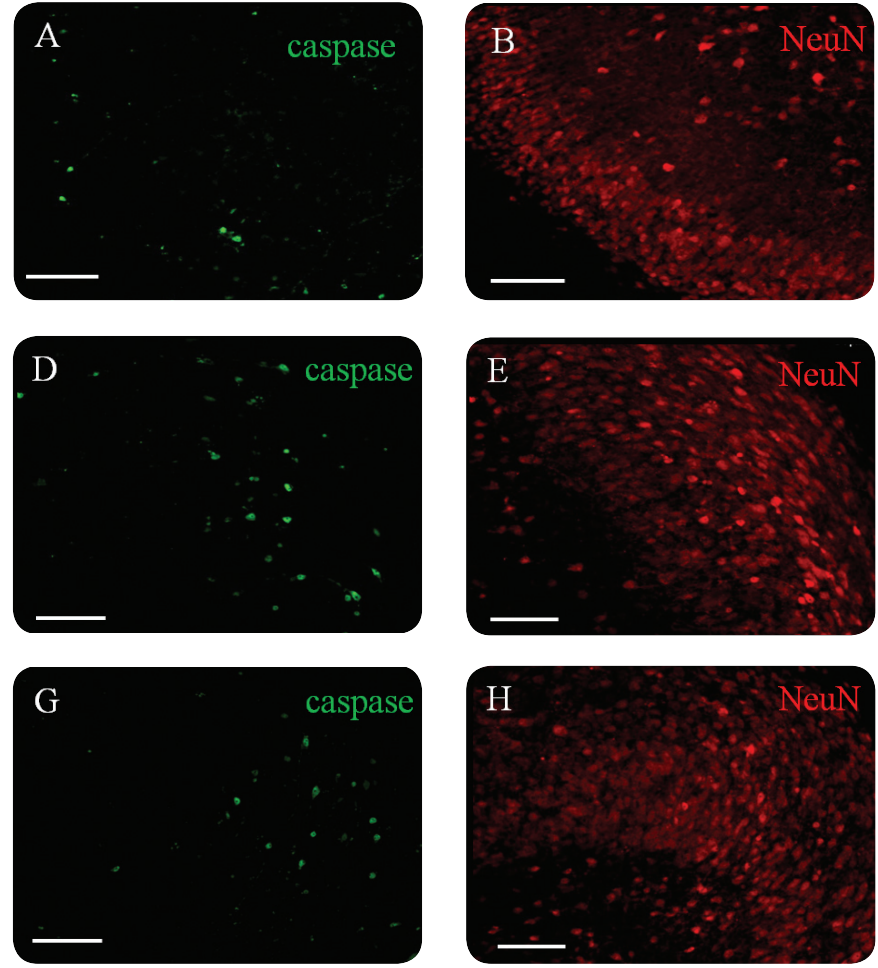
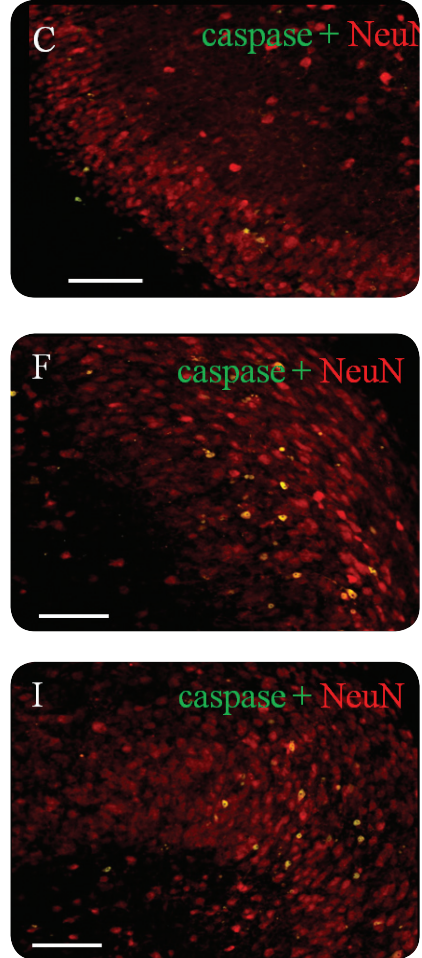

Fig. 1. Immunohistochemica staining of organotypical hippocampal slices for caspase3-positive nuclei of neuronal cells (green) and NeuN-positive nuclei of neurons (red), CA1 area. A-C - control group; D-F - 24 hours after OGD; G-I - 24 hours after OGD + BM-MMSCs. Scale $-50 \mu \mathrm{m}$. 
of cultured slices on the membrane, performing trophic and protective functions. In the organotypic hippocampal culture, there are stored all the cell types, which can be found in the hippocampus in vivo: pyramidal and granule neurons, interneurons and glial cells (astrocytes, microglia, oligodendrocytes ) [26, 27].

Thus, for a long time during the period of cultivation cytoarchitectonics, type specificity of cells, intercellular communication and other features characteristic of the living tissue remain in this organotypic culture of nervous tissue in vitro. At the same time it is much easier to manipulate experimentally than the model in vivo [28].

After the experimental oxygen-glucose deprivation in organotypic hippocampal culture of mice we observed damage of pyramidal neurons from CA1 hippocampal zone along with activation of glial cells (Fig. 1, 2). At the first hours after ischemic modeling in CA1 hippocampal area we found out an increase of glial cells immunoreactivity and structural reorganization of neurons.

In the hippocampal organotypic slice culture, undamaged neurons are uneven and lose their compact arrangement (Fig. 1). Between neurons we observed blanks and increased intercellular space. The emergence of numerous blanks in str. pyramidale and restructuring of compact arrangement of the pyramidal neurons is directly related to the death of neurons above (Fig. 1). At double immunohistochemical staining with markers caspase- 3 and NeuN there was found that ischemic damage significantly increased the number of caspase-3-positive nuclei of neurons. These results indicate that some neurons die by apoptosis mechanism. Mechanism of the pyramidal neurons death in $C A 1$ area at ischemia occurs by necrotic and apoptotic phenotype [29, 30].

Also, within 24 hours of the OGD process we observed reactive gliosis (Fig. 2). Microglial cells transformed from a state of rest, which is indicated by extensive net of processes that depart from the small soma, into amoeboid shape. Processes of such cells shortened and thickened, and size of soma significantly increased. In astrocyte cell phenotype we observed hypertrophy of the soma and processes. Such changes in the structure of glial cells are an indicator of the peak of reactive astrogliosis [31, 32].

Immunohistochemical analysis after 24 hours of BM-MMSCs cocultivation with $O G D$ after ischemia showed a significant reduction of caspase-3-positive nuclei of neural cells, as compared to those in ischemic damage without co-cultivation with BM-MMSCs, and reducing of hippocampal glial cells activation (Fig. 1, 2). After co-cultivation of hippocampal slices after OGD with BM-MMSCs, there remained cytoarchitectonics and type specificity of neural tissue cells. Neurons were located tightly and compactly, extracellular space decreased.

Co-cultivation of the OGD-treated slices with BM-MMSCs significantly improve the morphological status of the ischemic neural tissue. Bone marrow multipotent mesenchymal stromal cells in our model have shown neuroprotective effects. The direct mechanism of BM-MMSCS action in ischemic brain is still unknown. But we assume that such an improvement of morphological and functional state of the ischemic tissue takes place through activation of synaptogenesis, neurogenesis and neuroprotection due to growth factors, as noted by several authors [12, 33-35].

Thus, based on published data and our results, the use of stem cells in the treatment of ischemic effects of brain injury can take a leading position. At present this area of cell transplantation is under thorough experimental study. It is possible that in the future obtained positive results will be confirmed in clinical studies of the treatment effectiveness of ischemic brain injury.

\section{CONCLUSIONS}

IN THE CONDITIONS OF SHORT-TERM OGD THE NUMBER OF NEURONS IN ORGANOTYPIC HIPPOCAMPAL CULTURE REDUCES; AND ACTIVATION OF ASTROGLIAL AND MICROGLIAL CELLS IS OBSERVED. AT CO-CULTIVATION OF BM-MMSCS WITH ISCHEMIC NEURAL TISSUE, MORPHOLOGICAL STATE OF THE LATTER SIGNIFICANTLY IMPROVES AND NEUROPROTECTIVE EFFECT OF BM-MMSCS IS SHOWN.

ANALYSING OF OUR FINDINGS AND THE LITERATURE DATA, WE CAN ASSUME THAT IMPROVING OF MORPHOLOGICAL AND FUNCTIONAL STATE OF THE ISCHEMIC TISSUE TAKES PLACE THROUGH ACTIVATION OF SYNAPTOGENESIS, NEUROGENESIS AND NEUROPROTECTION DUE TO GROWTH FACTORS.
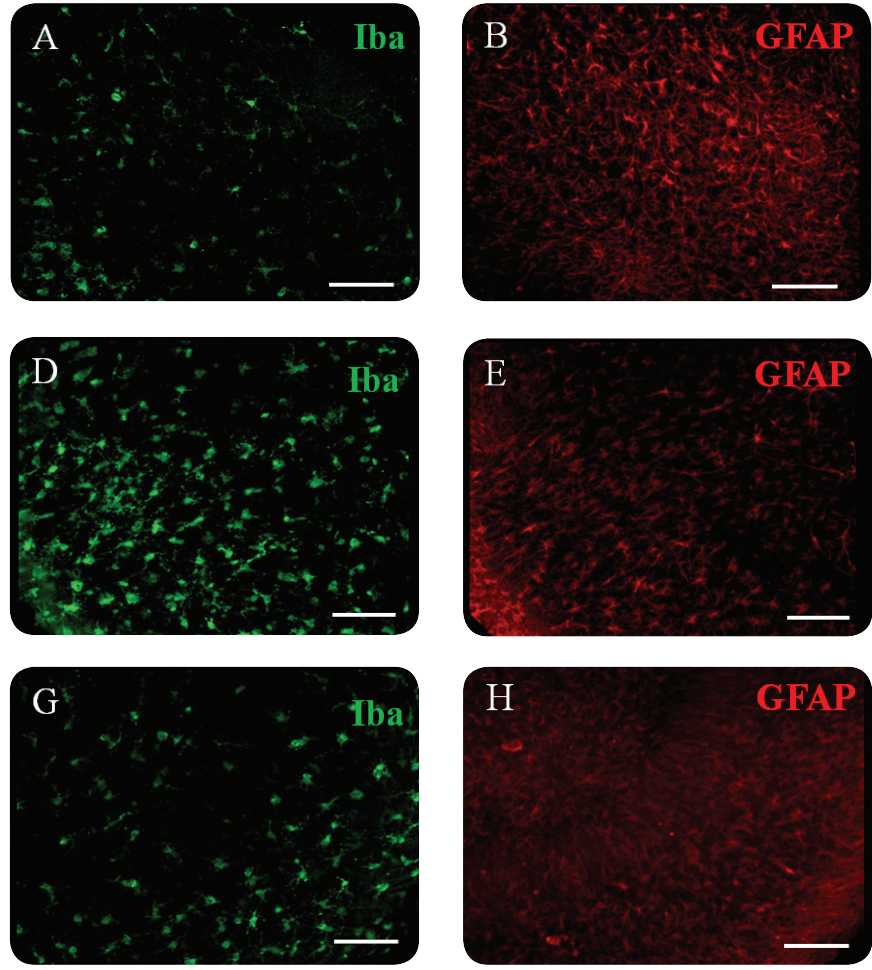

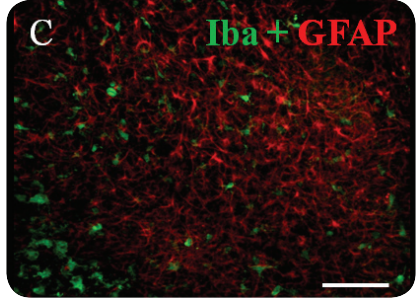

Fig. 2. Immunohistochemica staining of organotypical hippocampal slices for Iba - microglia (green) and GFAP - astroglia (red) CA1 area. $\mathbf{A - C}$ - control group D-F-24 hours after $O G D$; G-I - 24 hours after $O G D+$ BM-MMSCs. Scale $-50 \mu \mathrm{m}$.
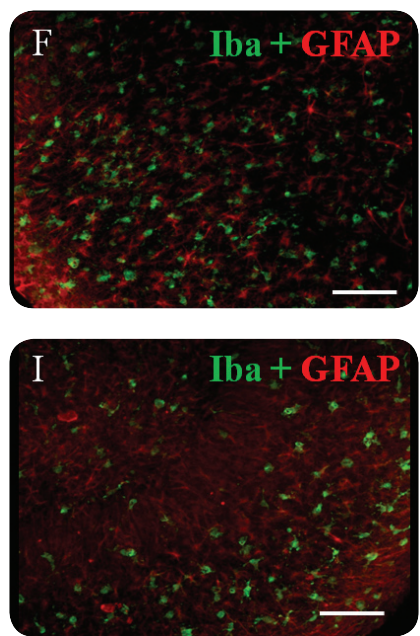


\section{REFERENCES}

1. Dirnagl U, ladecola C, Moskowitz M. Pathobiology of ischemic stroke: an integrated view. Trends Neurosci. 1999; 22:391-397.

2. Kristian T, Siesjo B. Changes in ionic fluxes during cerebral ischemia. Int. Rev. Neurobiol. 1997; 40:27-45.

3. Dunnett $S B$, Rosser AE. Clinical translation of cell transplantation in the brain.Curr Opin Organ Transplant. 2011; 16(6):632-639.

4. Miller RH, Bai L. Translating stem cell therapies to the clinic. Neurosci Lett. 2012; 519(2):87-92.

5. Mizusawa H. Brain ischemia - regenerative therapy using human neural stem cells. Rinsho Shinkeigaku. 2003; 43(11):832-833.

6. Secco M, Zucconi E, Vieira NM, et al. Multipotent stem cells from umbilical cord: cord is richer than blood! Stem Cells. 2008; 26(2):146-150.

7. Silva L, Arnold M. In search of the in vivo identity of mesenchymal stem cells. Stem Cells. 2008; 26(3):2287-2299.

8. Qiao C, Xu W, Zhu W, et al. Human mesenchymal stem cells isolated from the umbilical cord. Cell Biol. Int. 2008; 32(1):8-15.

9. Wang HS, Hung SC, Peng ST, et al. Mesenchymal stem cells in the Wharton's jelly of the human umbilical cord. Stem Cells. 2004; 22(7):1330-1337.

10. Petrenko AY, Grishchenko VI. Transplantacija stvolovyh kletok - terapija HHI veka. Harakteristika i svojstva stvolovyh kletok [Transplantation of stem cells - XXI century therapy. Characteristic and properties of stem cells]. Problemy Kriobiologii - Problems of Cryobiology, 2001; 16(2):3-12. (in Russian).

11. Zozulya YA, Lisyany NI. Nejrogennaja differencirovka stvolovyh kletok [The neurogenetic differentiation of stem cells]. Kiev, Jekspress poligraf, $2005.364 \mathrm{p}$.

12. Zubov DO, Oksymets VM. Osteoimunitet ta kul'tyvovani mezenhimal'ni stovburovi klityny [Osteoimmunity and the cultivated mesenchymal stem cells]. Problemy ekologii' ta ohorony pryrody tehnogennogo regionu: mizhvid. zb. nauk. pr. - Ecology and Environment of the anthropogenic region, 2008; 8:324-331.

13. Gimble JM, Guilak F, Nuttall ME, et al. In vitro differentiation potential of mesenchymal stem cells. Transfus. Med. Hemother. 2008; 35(3):228-238.

14. Repin VS. Jembrional'naja stvolovaja kletka (ot fundamental'noj biologii k medicine). [Embryonic stem cell (from fundamental biology to medicine)]. Uspehi fiziol. nauk - Success of Physiological Sciences, 2001; 32(1):3-19.

15. European convention for the protection of vertebrate animals used for experimental and other scientific purposes. Strasbourg. 1986, p.48.

16. Stoppini L, Buchs PA, Muller D. A simple method for organotypic cultures of nervous tissue. Jornal of Neuroscience Methods. 1997; 37(2):173-182.

17. Harting MT, Jimenez F, Cox CS. Isolation of Mesenchymal Stem Cells (MSCs) from Green Fluorescent Protein Positive (GFP+) Transgenic Rodents: The Grass Is Not Always Green(er). Stem cells and development. 2009; 18(1):127-135.

18. Ooi $Y Y$, Ramasamy $R$, Vidyadaran S. Mouse bone marrow mesenchymal stem cells acquire CD45CD106+ immunophenotype only at later passages. Med $J$ Malaysia. 2008; 63(suppl A):65-66.

19. Dominici $M$, Le Blanc K, Mueller I, et al. Minimal criteria for defining multipotent mesenchymal stromal cells. The International society for cellular therapy position statement.Cytotherapy. 2006; 8(4):315-317.

20. Daviaud N, Garbayo E, Schiller PC, et al. Organotypic cultures as tools for optimizing central nervous system cell therapies. Exp Neurol. 2013; 248:429-440.

21. Vinogradova O.S. Gippokamp i pamjat'. [Gippokamp and memory]. Moscow, Nauka, 1975. 267 p.

22. Gambaryan L.S., Kowal I.N. Gippokamp. Fiziologija i morfologija [Gippokamp. Physiology and morphology]. Yerevan, Academy of Sciences Armenian Soviet Socialist Republic, 1973. 104 p.

23. Peeters $C$, Hoelen D, Groenendaal $F$, et al. Deferoxamine, allopurinol and oxypurinol are not neuroprotective after oxygen/glucose deprivation in an organotypic hippocampal model, lacking functional endothelial cells. Brain Res. 2003; 963(12):72-80.

24. Kirino T, Sano K. Selective vulnerability in the gerbil hippocampus following transient ischemia. Acta Neuropathol. 1984; 62:201-208.

25. Winkelmann ER, Charcansky A, FaccioniHeuser MC. An ultrastructural analysis of cellular death in the CA1 field in the rat hippocampus after transient forebrain ischemia followed by 2, 4 and 10 days of reperfusion. Anat. Embryol. (Berl). 2006; 211(5):423-434.

26. Kettenmann H., Ransom B.R. Neuroglia. Edited by-2nd ed. Oxford. University Press, 2005. 601p.

27. Bahr BA. Longterm hippocampal slices: a model system for investigating synaptic mechanisms and pathologic processes. J. Neurosci. Research. 1995; 42(3): 294-305.

28. Laake J, Haug FM, Wieloch T, Ottersen O. A simple in vitro model of ischemia based on hippocampal slice cultures and propidium iodide fluorescence. Brain Research Protocols. 1999; 4(2):173-184.

29. Yuan J, Yankner BY. Apoptosis in the nervous system. Nature. 2000; 407:802-809.

30. Zeng YS, XU ZC. Coexistence of necrosis and apoptosis in rat hippocampus following transient forebrain ischemia . Neurosci Res. 2000; 37:113-125.

31. Wagner D, Scheibe J, Glocke I, Weise G, Deten A, Boltze J, Kranz A. Objectbased analysis of astroglial reaction and astrocyte subtype morphology after ischemic brain injury. Acta Neurobiol Exp (Wars). 2013; 73(1):79-87.

32. Sukumari Ramesh S, Alleyne $\mathrm{CH} \mathrm{Jr}$, Dhandapani KM. Astrocytespecific expression of survivin after intracerebral hemorrhage in mice: a possible role in reactive gliosis? J. Neurotrauma. 2012; 29(18):2798-804.

33. Kokaia Z, Lindvall O. Neurogenesis after ischaemic brain insults. Curr. Opin. Neurobiol. 2003; 13(1):127-132.

34. Nakatomi H, Kuriu T, Okabe S, Yamamoto S, Hatano O, Kawahara N, Tamura A, Kirino T, Nakafuku M. Regeneration of hippocampal pyramidal neurons after ischemic brain injury by recruitment of endogenous neural progenitors. Cell. 2002; 110(4):429-441.

35. Savitz SI, Rosenbaum DM, Dinsmore JH, Wechsler LR, Caplan LR. Cell transplantation for stroke. Ann Neurol. 2002; 52(3):266-275.

The authors indicate no potential conflicts of interest.

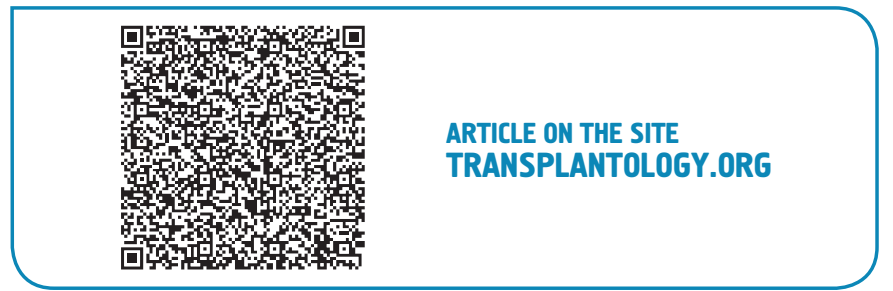

